\title{
Comparative study of solution concentration variations for polymer optical fibers sensor
}

\author{
Hazura Haroon *, Muhamad Naeem Mohd Nazri, Siti Khadijah Idris, Hanim Abdul Razak, Anis \\ Suhaila Mohd Zain, Fauziyah Salehuddin
}

Centre for Telecommunication Research \& Innovation (CeTRI), Fakulti Kejuruteraan Elektronik \& Kejuruteraan Komputer (FKEKK), Universiti Teknikal Malaysia Melaka (UTeM), Malaysia.

* Corresponding author: hazura@utem.edu.my

\section{Article history}

Received 22 February 2019

Revised 3 May 2019

Accepted 19 August 2019

Published Online 15 April 2020

\begin{abstract}
In this paper, we report a comparative study of fiber optic sensors for the application of aqueous solutions concentration monitoring. A simple, economical, and efficient set-up for liquid concentration measurement system was developed using polymer optical fibers (POFs). Cornstarch, sucrose, and salt solutions with different concentrations were tested, and the output power and the refractive index obtained were compared. The sensitivity of the sensor is found ranging from $0.938 \mu \mathrm{W} / \mathrm{RIU}$ to $96.9 \mu \mathrm{W} / \mathrm{RIU}$ in term of refractive index change and $0.04298 \mu \mathrm{W} / \mathrm{molL}^{-1}$ to $0.097 \mu \mathrm{W} / \mathrm{molL}^{-1}$ in terms of concentration. It has been found that the concentration is proportionally related to its refractive index where high refractive index will experience greater loss since the light rays tend to be refracted out of the fiber instead of being internally reflected. The experimental results also show that as the solution's concentration increases, the output power decreases.
\end{abstract}

Keywords: Fiber optic sensor, liquid concentration, optical fiber, refractive index, polymer optical fiber.

() 2020 Penerbit UTM Press. All rights reserved

\section{INTRODUCTION}

The technology and applications of optical fibers have progressed very rapidly in recent years. Fiber optic technology offers many advantages such as high sensitivity, immunity to electrical noises, relatively small size, geometrical flexibility, and the possibility of realtime monitoring and remote sensing (Pospísilová et al., 2015; Haroon et al., 2018, 2017; Tran et al., 2018). Due to these advantages, this technology has been exploited for various applications including communication systems, chemical, bio-medical sensing, civil, and automotive (Güemes et al., 2016; Tosi et al., 2018; Razak et al., 2018; Hanim et al., 2018). The working principle of fiber optic sensor (FOS) is based on light modulation due to environmental or external perturbation, which changes its wavelength, phase, intensity, or polarization.

With the progress in polymer fiber technologies, there has been great interest in the use of polymer optical fibers (POFs) for sensing applications. This is due to their low cost and mechanical properties (Luo. et al., 2017; Arifin et al., 2017; Peters, 2010). This multimode fiber has the numeric aperture around $0.4-0.5$ and attenuation of around of $1 \mathrm{~dB} / \mathrm{m}$ at $650 \mathrm{~nm}$.

The solution concentration is one of the key parameters in solution characterizations. Many industries have made every effort on monitoring and controlling the solution-concentration properties particularly in paper-making, chemicals, sugar-manufacturing, food, bio-medical, and pharmaceutics industries. This is a crucial step for guaranteeing and improving product quality. Hence, it is of significant importance to analyze the concentration of certain solutions (Wang et al., 2015; Joe et al., 2018; Liu et al., 2017).

The goal of this article is to develop an FOS to detect liquid concentration variations. To increase the sensitivity of the optical transmission loss to a specific concentration, a cladding of a $1000 \mu \mathrm{m}$ core diameter, multi-mode, polymethylmethacrylate (PMMA) POF was removed. Different liquid concentrations will exhibit different refractive index (RI) value (Banerjee et al., 2007; Liu et al., 2015). The core contacts the test liquid directly and modulates the transmitted light energy by its RI. Therefore, the light intensity at the removal part of the fiber optic will vary with the change of test liquid concentration, due to the change in RI value. By comparing the response of the uncoated fiber optic sensor for several solutions, the effect of the liquid concentration on output power by different concentrations is observed.

\section{EXPERIMENTAL SETUP}

The optical fiber used is made of PMMA-plated fiberglass multimode optical fiber with a jacket and cladding diameters of $2.2 \mathrm{~mm}$ and $1.0 \mathrm{~mm}$, respectively. Fig. 1 shows the experimental system setup of the solution-concentration FOS. The infra-red LED light source at $850 \mathrm{~nm}$ wavelength is connected to a POF that has been uncladded by submerging in acetone. The exposed core was employed to sense the RI of various liquids at room temperature. The optical signal was transmitted to the RY3200A optical power meter (OPM) to monitor the 
output. The length for POF cable was fixed at 1 meter and the exposed area, which is the sensing area, has been stripped to 2 centimeters of length by using a fiber cutter.

The power $P_{t}$ transmitted for a multimode polymer optical fiber with removed cladding is generally expressed as

$$
P_{t}=P_{o} \exp \left[-C_{\gamma} \int_{0}^{L} \varphi(z) d z\right]
$$

where $P_{o}$ is the initial power transmitted, $C$ is the concentration of solution sample, $g$ is the coefficient of absorption per concentration in the case of free-beam optics, $z$ is the distance along the uncladded portion of fiber, $\varphi(z)$ is the fractional power outside the fiber core, and $L$ is the length of the uncladded portion of fiber (Choudhury et al., 2004). It can be predicted from Eq. (1) that the transmitted power is inversely proportional to both the uncladded length of the fiber and the concentration of the solution.

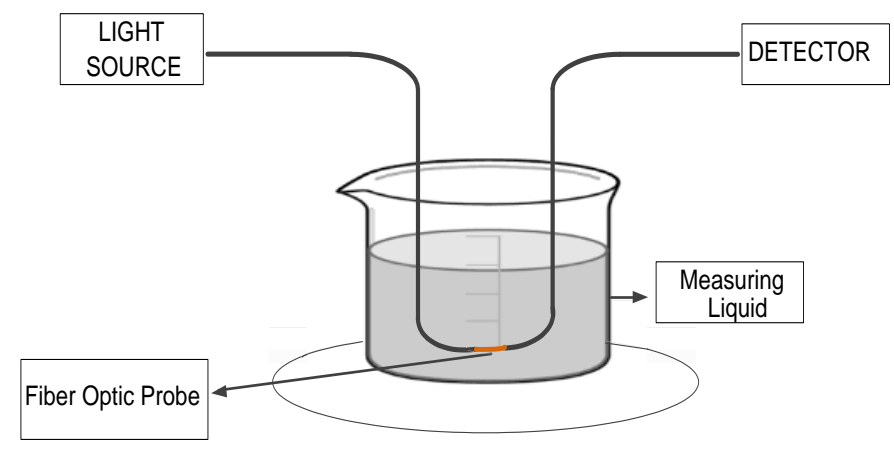

Fig. 1 Optical experimental setup.

\section{RESULTS AND DISCUSSION}

\section{Fabrication of POF sensor probe}

Fabrication of POF probe is a process of making the fiber as a sensing area section. The jacket of the fiber must be removed using a fiber cutter by carefully stripping the fiber. Next, the exposed area of the fiber was cleaned using an alcohol solution. To create the sensitive part of the sensor, the cladding was fully removed, thus exposing the core of the fiber where it will act as the sensor probe. This allows the core layer to contact the environment directly for sensing purposes.

The removal of the cladding can be done either by rubbing a sandpaper on the cladding of the fiber or by an etching process using the etcher such as acetone. In this paper, the uncoated fibers were immersed in acetone at different etching times to determine the duration that will produce the most optimum thickness of fiber. The etching period was varied from 2 to 10 seconds, each with 2 seconds increment. For every etching time, 5 identical samples were used and the average fiber thickness was calculated. The fiber thickness was monitored by using ZEISS Axioskop 2 MAT Image Analyzer.

Fig. 2 portrays the image of the POF core after the cladding was removed by using sandpaper. It was found that it is hard to control the size of the core diameter since the process was carried out manually. Therefore, it is recommended to remove the cladding by using etcher as the fiber's thickness can be estimated.

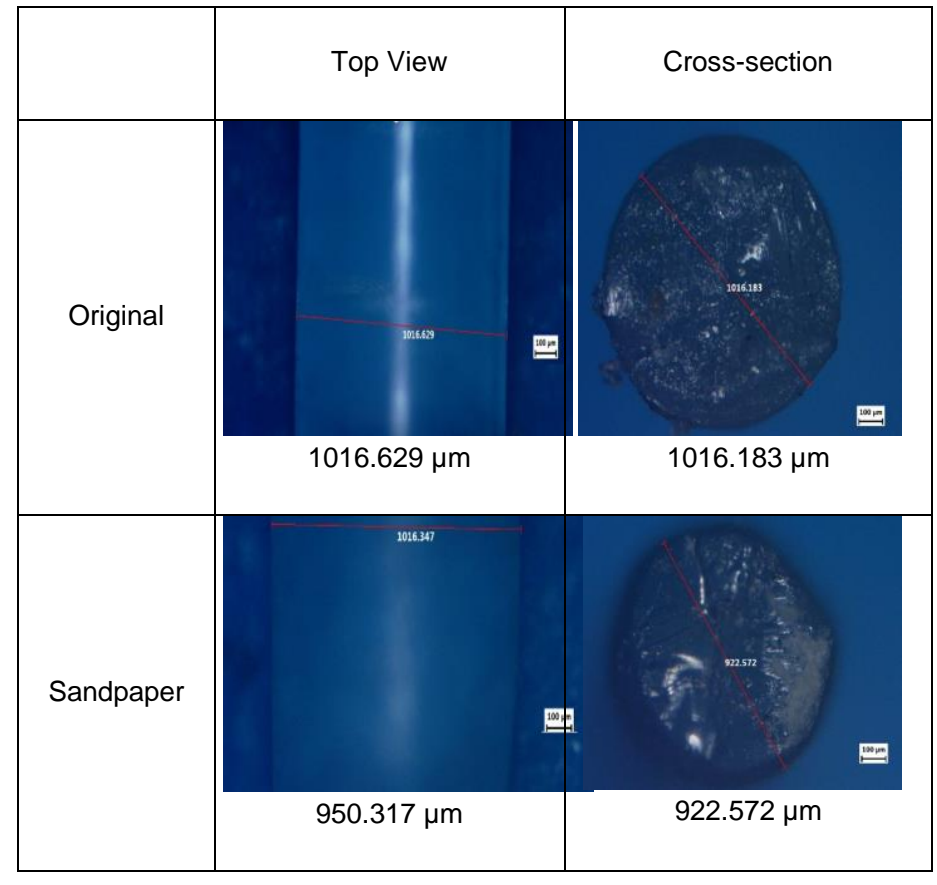

Fig. 2 Top and cross-sectional views of an original POF and an uncoated POF.

The average diameter width measured from the cross-section and top views for 5 different etching times are summarized in Table 1 . Based on Table 1, it is shown that the most suitable time to etch the cladding is 2 seconds because the fiber core and coating are sufficiently removed. Only a small exposed area is needed, therefore it is adequate if the core diameter is slightly less than $1000 \mu \mathrm{m}$. Further etching will cause damage to the fiber optic. Over etching happens when the size of the core of the fiber has been greatly reduced thus making the fiber fragile. Small discrepancy between the measurement taken from the top view and side view is due to the uneven fiber etching.

Table 1 The thickness of fibers after being immersed in acetone at different etching times from side and top views.

\begin{tabular}{ccc}
\hline Time & Side View $(\boldsymbol{\mu m})$ & Top View $(\boldsymbol{\mu m})$ \\
\hline 2 Seconds & 997.425 & 989.454 \\
4 Seconds & 993.235 & 977.985 \\
6 Seconds & 989.544 & 971.960 \\
8 Seconds & 983.807 & 964.294 \\
10 Seconds & 975.702 & 950.804 \\
\hline
\end{tabular}

\section{Preparation of Aqueous Solutions}

Aqueous solutions of sucrose $\left(\mathrm{C}_{12} \mathrm{H}_{22} \mathrm{O}_{11}\right)$, salt $(\mathrm{NaCl})$, and cornstarch $\left(\mathrm{C}_{6} \mathrm{H}_{10} \mathrm{O}_{5}\right)$ were used as the samples. Using Eq. 2, the mass of the solutes needed was determined as shown in Table 2. Next, the solutions were prepared by dissolving the measured solutes in water. The concentration of the solution was determined by using Eq. 3 . Finally, the solution's RI was determined by using DR-101 Digital Refractometer as tabulated in Table 3. From Table 3, it is obvious that the liquid concentration and mass are directly proportional to the RI.

$$
\text { Number of Moles }=\frac{\text { Mass of Solute }}{\text { Molar Mass of Solute }}
$$

Concentration of Solution $=\frac{\text { Number of Moles }}{\text { Volume of Solvent }}$ 
Table 2 Mass of solute for various volume concentrations.

\begin{tabular}{lcc}
\hline Solute & Number of Moles & Mass of Solute, $\mathbf{g}$ \\
\hline \multirow{4}{*}{ Sucrose } & $0.1 \mathrm{~mol}$ & 17.1 \\
& $0.3 \mathrm{~mol}$ & 51.3 \\
& $0.5 \mathrm{~mol}$ & 85.6 \\
& $0.8 \mathrm{~mol}$ & 136.9 \\
& $1.0 \mathrm{~mol}$ & 171.1 \\
& $1.5 \mathrm{~mol}$ & 256.7 \\
Salt & $2.0 \mathrm{~mol}$ & 342.3 \\
& $1.0 \mathrm{~mol}$ & 29.2 \\
& $2.0 \mathrm{~mol}$ & 58.4 \\
& $3.0 \mathrm{~mol}$ & 87.6 \\
& $4.0 \mathrm{~mol}$ & 116.8 \\
Cornstarch & $5.0 \mathrm{~mol}$ & 146.0 \\
\hline & $0.2 \mathrm{~mol}$ & 16.2 \\
& $0.4 \mathrm{~mol}$ & 32.4 \\
& $0.6 \mathrm{~mol}$ & 48.6 \\
& $0.8 \mathrm{~mol}$ & 64.9 \\
& $1.0 \mathrm{~mol}$ & 81.0
\end{tabular}

Table 3 The refractive index of solutions for different volume concentrations.

\begin{tabular}{lll}
\hline Type of Solution & Number of Moles & $\begin{array}{l}\text { Refractive } \\
\text { Index }\end{array}$ \\
\hline Air & & 1.0000 \\
\hline Water & $0.1 \mathrm{~mol}$ & 1.3333 \\
\hline & $0.3 \mathrm{~mol}$ & 1.3388 \\
& $0.5 \mathrm{~mol}$ & 1.3557 \\
Sucrose & $0.8 \mathrm{~mol}$ & 1.3676 \\
& $1.0 \mathrm{~mol}$ & 1.3849 \\
& $1.5 \mathrm{~mol}$ & 1.3901 \\
& $2.0 \mathrm{~mol}$ & 1.4031 \\
\hline \multirow{3}{*}{ Salt } & $1.0 \mathrm{~mol}$ & 1.3437 \\
& $2.0 \mathrm{~mol}$ & 1.3536 \\
& $3.0 \mathrm{~mol}$ & 1.3617 \\
& $4.0 \mathrm{~mol}$ & 1.3685 \\
& $5.0 \mathrm{~mol}$ & 1.3768 \\
\hline \multirow{3}{*}{ Cornstarch } & $0.2 \mathrm{~mol}$ & 1.3320 \\
& $0.4 \mathrm{~mol}$ & 1.3321 \\
& $0.6 \mathrm{~mol}$ & 1.3322 \\
& $0.8 \mathrm{~mol}$ & 1.3323 \\
& $1.0 \mathrm{~mol}$ & 1.3324 \\
\hline
\end{tabular}

\section{Optical measurement analysis}

In this experiment, three groups of solutions with varied concentrations were studied, namely cornstarch, sucrose, and salt solutions. For the optical characterizations, the FOS was connected to the light source as input and the other end was connected to the Optical Power Meter for the output reading. The input wavelength used was $850 \mathrm{~nm}$. Fig. 3 shows the output power when the fiber probe was soaked in DI water and different solutions.

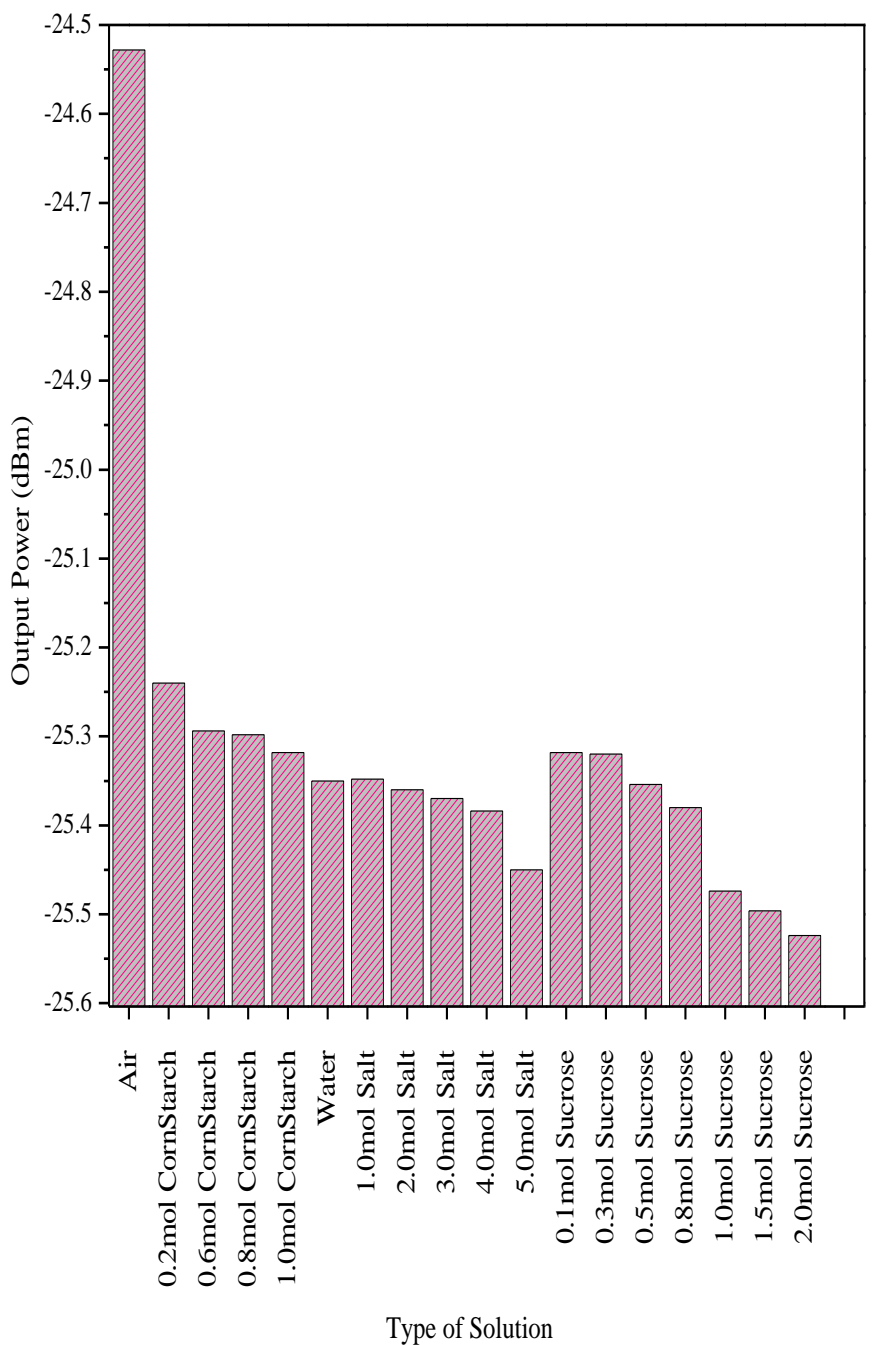

Fig. 3 Optical output power in dbm for various solutions.

Based on the bar chart, it shows that the liquid concentration is closely related to the sensor output. It is observed that the output power decreases as the concentration of the aqueous solutions increases.

\section{Mathematical model of fiber optic sensor for liquid type detection}

Fig. 4 shows the linear fitting curve for the output power response against RIU for the cornstarch solution. From the graph, the mathematical expression that relates the output power and effective RI can be formulated as

$$
P_{\mu W}=-96.6 \mu\left(n_{e f f}\right)+131.65 \mu W
$$

where $P \mu W$ is the transmitted output power in $\mu \mathrm{W}$ and $n_{\text {eff }}$ is the effective RI value. By plotting the output response for other aqueous solutions as depicted in Fig. 5 and Fig. 6, the mathematical model derived are as in Table 4. From both graphs, we can see that the solution concentration changes are inversely proportional to the RI. This is consistent with Clausius-Mosetti equation, which states that the output power decreases as the RI increases (Kumar, 2006).

The slope of the line graph represents the sensitivity of the fiber when interacting with specific aqueous solutions. Referring to Fig. 4 to Fig. 6 , cornstarch has the highest sensitivity, indicated by the steepest slope value of $96.6 \mu \mathrm{W} / \mathrm{RIU}$. 


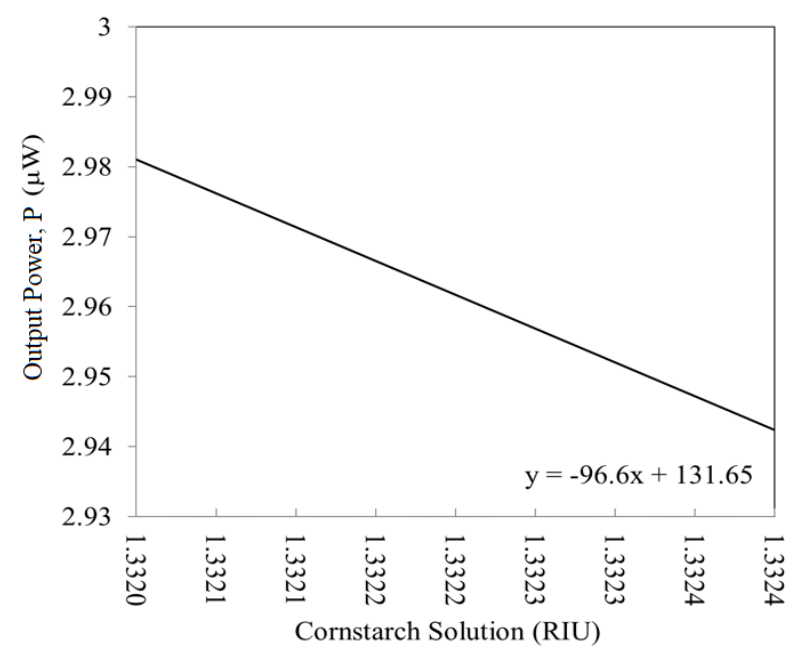

Fig. 4 Sensor readings for different RI of cornstarch solution.

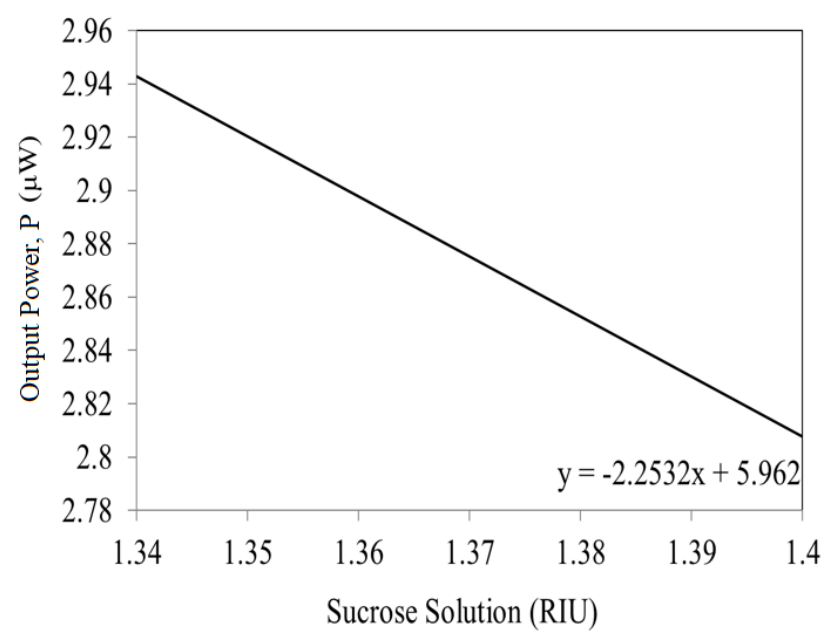

Fig. 5 Sensor readings for different RI of sucrose solution.

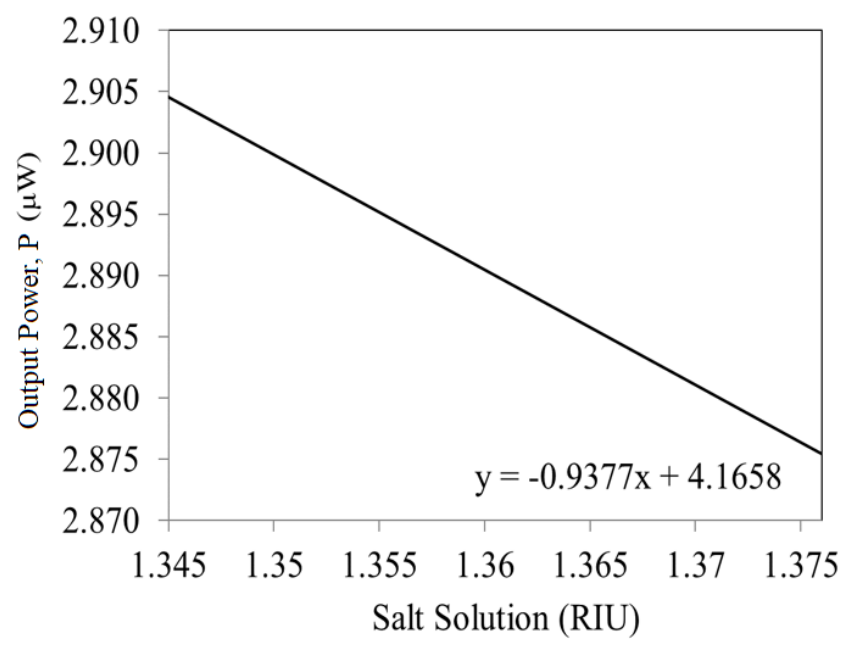

Fig. 6 Sensor readings for different RI of salt solution.
Table 4 Mathematical model for the relationship of output power and RI unit.

\begin{tabular}{lc}
\hline Type of Solution & Mathematical Modelling \\
\hline Cornstarch & $P_{\mu W}=-96.63 \mu($ neff $)+131.65 \mu \mathrm{W}$ \\
Sucrose & $P_{\mu W}=-2.253 \mu($ neff $)+5.96 \mu \mathrm{W}$ \\
Salt & $P_{\mu m}=-0.938 \mu($ neff $)+4.166 \mu \mathrm{W}$ \\
\hline
\end{tabular}

In order to investigate the response of the sensor towards liquid concentration, the received power for each solution with different concentration was observed. From Fig. 7 to Fig. 9, it can be clearly seen that the responses for cornstarch, sucrose, and salt solutions show a similar trend. The mathematical model for all three solutions in conjunction with the concentration value are summarized in Table 5. The sensitivities of the FOS in detecting the concentration variation for cornstarch, sucrose, and salt are $0.4298 \mu \mathrm{W} / \mathrm{molL}^{-1}, 0.024 \mu \mathrm{W} / \mathrm{molL}^{-1}$, and $0.0079 \mu \mathrm{W} / \mathrm{molL}^{-1}$, respectively. By comparing the output with the work done by Musa et al., which applied FBG-based optical sensor for liquid concentration measurement, the present study reports an improved sensitivity for sucrose and salt concentration.

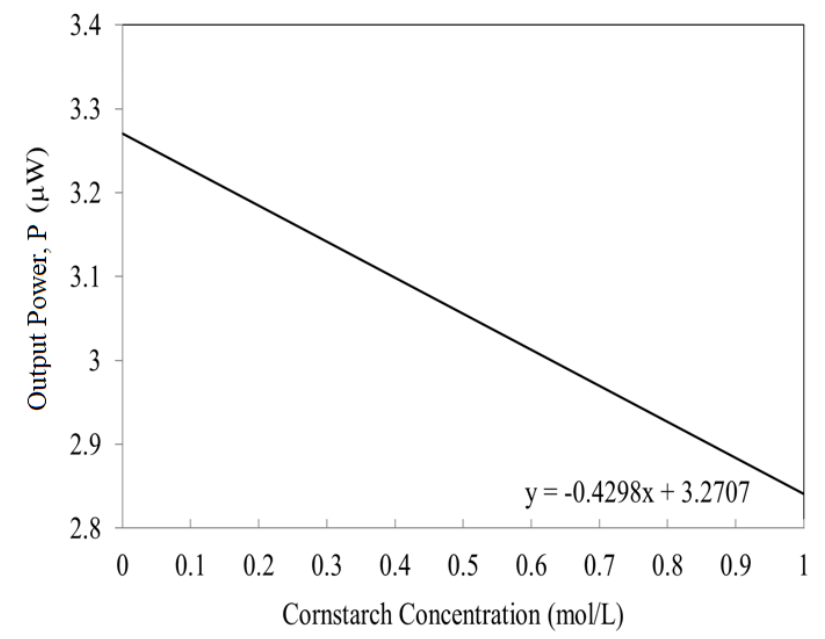

Fig. 7 Sensor readings for different concentration of cornstarch solution.

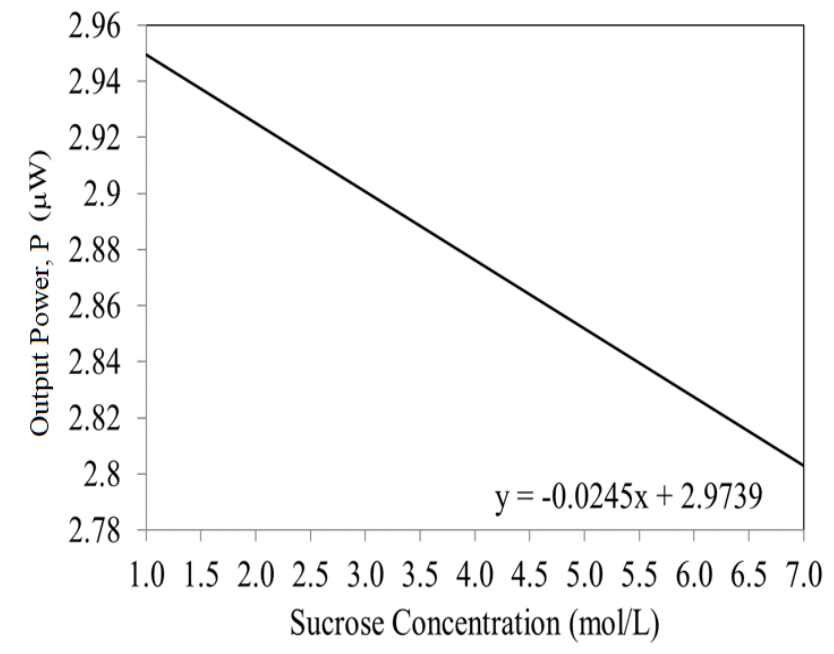

Fig. 8 Sensor readings for different concentration of sucrose solution. 


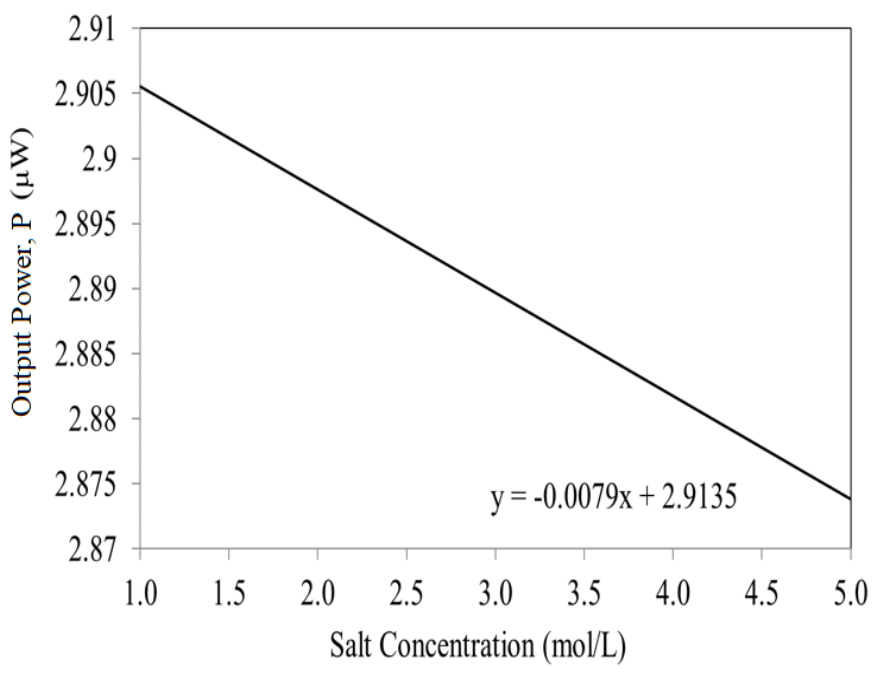

Fig. 9 Sensor readings for different concentration of salt solution.

Table 5 Mathematical model for the relationship of output power and liquid concentration.

\begin{tabular}{lc}
\hline \multicolumn{1}{l}{ Type of Solution } & \\
\hline Cornstarch & $P_{\mu W}=-0.4298 \mu \mathrm{W} / \mathrm{molL}^{-1}-+3.2707 \mu \mathrm{W}$ \\
Sucrose & $P_{\mu W}=-0.0245 \mu \mathrm{W} / \mathrm{molL}^{-1}+2.974 \mu \mathrm{W}$ \\
Salt & $P_{\mu W}=-0.0079 \mu \mathrm{W} / \mathrm{molL}^{-1}+2.914 \mu \mathrm{W}$ \\
\hline
\end{tabular}

\section{CONCLUSION}

In conclusion, a method of developing an FOS for liquid concentration monitoring has been proposed and experimentally verified with good results. Three liquid samples with different concentrations were investigated by using the unclad FOS. Experimental results show that all the samples have good sensitivity and the sensor is excellent in detecting concentration variation of salt solution with the highest sensitivity of $96.6 \mu \mathrm{mW}$ RIU in the RI range of 1.3320 to 1.3324 . Future works will be emphasized on optimizing the sensor performance and reliability.

\section{ACKNOWLEDGEMENT}

The authors would like to thank Universiti Teknikal Malaysia (UTeM), Melaka and Ministry of Higher Educations (MOHE) for supporting this research.

\section{REFERENCES}

A. Güemes, A. F. López, P. F. D. Maroto, A. Lozano, J. S. Perez. 2018. Structural health monitoring in composite structures by fiber-optic sensors. Sensors (Basel) 18(4), 1084.

A. J. Kumar, N. M. Gowri, R. V. Raju, G. Nirmala, B. S. Bellubbi, T. R. Krishna. 2006. Study of fiber optic sugar sensor. Pramana-Journal of Physics 67(2), 383-387.

A. Q. Liu, Y. Liu, S. Chen, F. Wang, W. Peng. 2017. A low-cost and portable dual-channel fiber optic surface plasmon resonance system. Sensors 17, 2797.

A. Arifin, I. Irwan, B. Abdullah, D. Tahir. Design of sensor water turbidity based on polymer optical fiber. 2017. 2017 International Seminar on Sensors, Instrumentation, Measurement and Metrology (ISSIMM). August 25-26, Surabaya.

A. R. Hanim, H. Hazura, A. S. M. Zain, S. K. Idris. 2018. Modal interferometer structures and splicing techniques of fiber optic sensor. Journal of Telecommunication, Electronic and Computer Engineering (JTEC) 10 (2-2), 23-27.

A. Banerjee, S. Mukherjee, R. Verma, B. Jana. 2007. Fiber optic sensing of liquid refractive index. Sensors and Actuators B 123, 594-605.

D. Liu, A. Mallik, J. Yuan, C. Yu, G. Farrell, Y. Semenova, Q. Wu. 2015. High sensitivity refractive index sensor based on a tapered small core single-mode fiber structure. Optic Letters 40(17), 4166-4169.

Tosi, S. Poeggel, I. Ordachita, E. Schena. 2018. Fiber optic sensors for biomedical applications. Opto-Mechanical Fiber Optic Sensors, 301-333.

H. A. Razak, N. H. Sulaiman, H. Haroon, A. S. M. Zain. 2018. A fiber optic sensor based on Mach-Zehnder interferometer structure for food composition detection. Microwave and Optical Technology Letters 60(4), 920-925.

H. Haroon, and S. S. Khalid. 2017. An overview of optical fiber sensor applications in liquid concentration measurements. Journal of Advanced Review on Scientific Research 36 (1), 1-7.

H. Haroon, S. K. Idris, M. Y. Yusoff, A. S. M. Zain, H. A. Razak, F. Salehuddin, M. Z. N. Syaimaa. 2018. design and implementation of fibre optic sensor for soil moisture detection. Journal of Telecommunication, Electronic and Computer Engineering (JTEC) 10(2-5), 131-134.

H.-E. Joe, H. Yun, S.-H. Jo, M. B.G. Jun, B.-K. Min. 2018. A review on optical fiber sensors for environmental monitoring. International Journal of Precision Engineering and Manufacturing-Green Technology 5(1), 173-191.

K. Peters. 2010. Polymer optical fiber sensors-a review. Smart Materials and Structures 20(1), 013002.

M. Pospíšilová, G. Kuncová, J. Trögl. 2015. Fiber-optic chemical sensors and fiber-optic bio-sensors. Sensors 15, 25208-25259.

P. K. Choudhury, T. Yoshino. 2004. On the fiber-optic chlorine sensor with enhanced sensitivity based on the study of evanescent field absorption spectroscop. Optik 115 (7), 329-333.

R. K. Musa, S. Al deen, A. Taha, A. M. Hammadi. 2017. Tipped fiber bragg grating sensor for concentration measurements. International Journal of Computation and Applied Sciences IJOCAAS, 2(3), 123.

V. T. Tran, N. H. T. Tran, T. T. Nguyen, W. J. Yoon, H. Ju. 2018. Liquid cladding mediated optical fiber sensors for copper ion detection. Micromachines 9, 471(1-9).

X.-d. Wang, O. S. Wolfbeis. 2015. Fiber-optic chemical sensors and biosensors (2013-2015). Analytical Chemistry, 88(1), 203-227.

Y. Luo, B. Yan, Q. Zhang, G.-D Peng, J. Wen, J. Zhang. 2017. Fabrication of polymer optical fibre (POF) gratings. Sensors (Basel)17 (3), 511. 